\title{
Cold atmospheric argon plasma jet source and its application for bacterial inactivation
}

\author{
Bair B. Baldanov ${ }^{1}$ (1) $\cdot$ Tsyrempil V. Ranzhurov $^{1} \cdot$ Alexander Petrovich Semenov $^{1} \cdot$ Sayana V. Gomboeva ${ }^{2}$
}

Received: 19 November 2018 / Accepted: 14 April 2019 / Published online: 26 April 2019

(c) The Author(s) 2019

\begin{abstract}
In this work, the efficiency of inactivation of a cold argon plasma jet at atmospheric pressure (APPJ) on the basis of a lowcurrent spark discharge into microorganisms with different characteristics of the cell walls was evaluated. Gram-negative bacteria Escherichia coli M17, gram-positive bacteria Bacillus subtilis 534 and Bacillus cereus IP 5832, and the yeast Saccharomyces cerevisiae were seeded on cultured Petri dishes. A plasma jet with an average power of $0.85 \mathrm{~W}$ and a flow rate of argon of $6.7 \mathrm{l} / \mathrm{min}$ was directed perpendicular to the Petri dishes with agar. The distance to the agar varied from 0.5 to $3 \mathrm{~cm}$, and the treatment time varied from 5 to $300 \mathrm{~s}$. The efficiency of inactivation was assessed by measuring the area of inactivation zones (where there was no growth of microorganisms). It was shown that gram-negative bacteria E. coli M17 is most susceptible to exposure to the plasma jet, and gram-positive bacteria B. cereus IP 5832 and yeast S. cerevisiae are most stable. It is established that an increase in the treatment time of plasma jets of a low-current spark allows effective inactivation of microorganisms over a much larger area.
\end{abstract}

Keywords Argon plasma · Microorganisms · Low-current spark · Plasma jets · Plasma inactivation · Atmospheric-pressure glow discharge

\section{Introduction}

Investigation of properties of gas-discharge processes aimed at determining the possibility of their application for sterilization and disinfection treatment in protecting industrial materials, equipment, and electronics from biological damage and microbiologically induced corrosion has become of vital importance at present $[1,2]$. Plasma treatment of living tissues produces the desirable therapeutic effect in sterilization and arrest of bleeding, bleeding control, and cure of some skin diseases [3, 4]. This trend has acquired special importance in recent years due to the increasing need of mankind in new high-productive sterilization and disinfection technologies that do not require high temperatures, are simple in operation, and are characterized by high effectiveness and reliability.

Bair B. Baldanov

baibat@mail.ru

1 Institute of Physical Material Science, Siberian Branch, Russian Academy of Sciences, Ulan-Ude, Russia

2 East-Siberian State University of Technologies and Management, Ulan-Ude, Russia
Among plasma technologies, analysis of discharges generating low-temperature (cold) nonequilibrium plasmas under atmospheric pressure is of special importance [5-11]. Various types of gas discharges that can serve as sources of a low-temperature nonequilibrium plasma include the creeping discharge, corona, barrier, and pulsed discharges under atmospheric pressure. In spite of the large number of publications (see, for example, $[8,9,12,13]$ ) devoted to analysis of various characteristics of discharges and the well-proven high effectiveness of application of discharges for biomedical purposes on the laboratory scale, the treatment with cold plasma under atmospheric pressure aimed at inactivation of microorganisms has not found wide application. This is primarily due to the fact that cold plasma sources require technically complicated equipment with a low economic efficiency. Second, the atmospheric-pressure discharges for treatment of biological objects require high voltages $(10-40 \mathrm{kV})$, which necessitates a high safety level to be ensured. For this reason, the choice of discharge parameters for which safe and nondestructive action is ensured is one of the main physical problems in plasma medicine. Most plasma jets have a diameter of a few millimeters. On the basis of the low-current spark discharge in argon at 
atmospheric pressure, it is possible to receive homogeneous enough plasma jets of big diameters which are perspective, for example, in medicine for treatment of vast wounds [14].

In the present work, three species representative of different microbial groups were treated in order to evaluate the inactivation efficiency of cold atmospheric-pressure plasma jet. Gram-positive bacteria possess thick cell walls composed by several layers of peptidoglycan. Differently from gram-negative bacteria, they are absent of bacterial outer membrane. Gram-negative bacteria exhibit clearly layered structure with three main sections: the outer membrane, the peptidoglycan cell wall, and the inner membrane. The outer membrane plays important role in protecting the cell against toxic molecules and providing an extra stabilizing layer around the cell $[15,16]$. Fungi are eukaryotic cells, and their cell walls are completely different from the prokaryotic ones (bacteria). Fungal cell walls are very thick and composed by rigid polysaccharide layers, such as chitin. It is responsible for providing structural strength to fungi cell walls making them more resistant to harmful extracellular agents [17]. Due to these noticeable structural differences of the selected microorganisms, it is expected that different responses to the plasma treatment would occur. Here, the gram-positive bacterium Bacillus subtilis 534 and Bacillus cereus IP 5832, the gram-negative bacterium Escherichia coli M17, and the fungus Saccharomyces cerevisiae were plated on standard Petri dish filled with culture media and then exposed to plasma. The effect of the distance between plasma plume and agar surface was also investigated.

\section{Materials and methods}

\section{Experimental setup}

We have developed a nonequilibrium plasma source operating under atmospheric pressure for generating low-temperature (cold) plasma based on plasma jets of a low-current spark discharge $[10,14]$ under the atmospheric pressure (Fig. 1). The cathode (point 1 with radius of curvature $r=30 \mu \mathrm{m}$ ) is placed in an insulating casing in the form of a tube of radius $R=2 \mathrm{~cm}$. The anode is a metal cylinder $1.5 \mathrm{~cm}$ in length and $2 \mathrm{~cm}$ in diameter. For stabilizing the discharge, the point is loaded with a controllable high ballast resistance $\mathrm{Rb}(>1 \mathrm{M} \Omega)$. The casing has intake orifices for puffing argon, which are arranged so that cold argon plasma produced by a system of plasma jets from low-current spark propagates in the direction from the electrode gap with an argon flow like a flame. Argon flow rate $\mathrm{G}$ is measured by PM-A-0.16 GUZ rotameter up to $5 \times 10^{-5} \mathrm{~kg} / \mathrm{s}$.

The averaged current of a discharge was measured with $\mathrm{M}$ 906 pointer microammeter. The waveforms and amplitudes

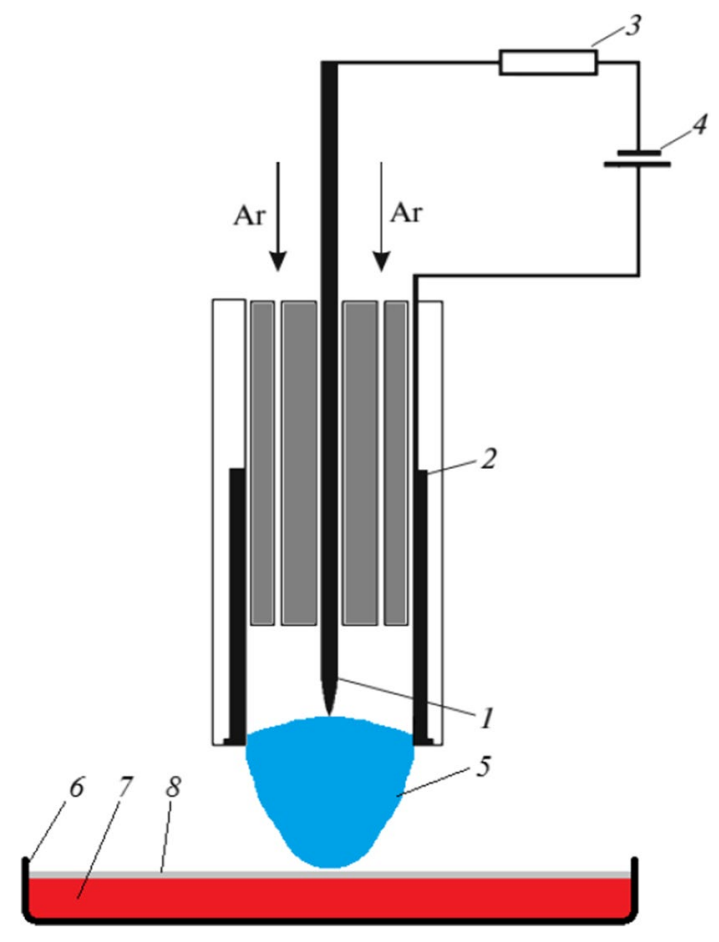

Fig. 1 Schematic diagram of experimental setup: (1) point cathode; (2) cylindrical anode; (3) ballast resistance; (4) power supply (5) plasma jet; (6). Petri dish; (7) culture medium; and (8) microbial suspension

of the pulsed current component were monitored using lowinductive current shunts and S1-65 oscilloscope.

\section{Microorganisms and preparation of inoculum}

\section{Bacterial strains}

Bacterial strains used in the study: E. coli $\mathrm{M} 17$, B. subtilis 534, B. cereus IP 5832, and S. cerevisiae, were obtained from the collection of microorganisms from the Biotechnology Department, Institute of Food Engineering and Biotechnology, East-Siberian State University of Technology and Management (Ulan-Ude, Russia). Cultures were stored on nutrient media at $4{ }^{\circ} \mathrm{C}$.

\section{Preparation of inoculum}

To prepare the inoculum, the studied bacteria were incubated on nutrient media for $48 \mathrm{~h}$ at $28^{\circ} \mathrm{C}($ S. cerevisiae $)$ and for $24 \mathrm{~h}$ at $37{ }^{\circ} \mathrm{C}$ (E. coli M17, B. subtilis 534, B. cereus IP 5832), and then, the daily cell culture was suspended in sterile water. The results of the quantitative determination of microorganisms, carried out according to the Koch method, were expressed in colony forming units (CFU). Initial cell concentrations were obtained: $9.14 \log \mathrm{CFU} / \mathrm{ml}$ for $E$. coli M17, $7.83 \log$ CFU/ml for B. subtilis 534, $8.47 \log$ CFU/ml 
for B. cereus IP 5832, and $7.14 \log$ CFU/ml for S. cerevisiae. All samples were analyzed in triplicate, and the given value is the average value of three determinations.

To evaluate the sensitivity of microorganisms to cold argon plasma generated by low-current spark discharge plasma jets, a method was used based on measuring the diameter of the inactivation zone, which manifests itself as a clean area on a nutrient medium. Therefore, a medium was inoculated with test microorganisms. About $100 \mu l$ of working suspension was added into a Petri dish with nutrient medium and carefully rubbed with a spreader. Bacillus subtilis was seeded on RPA, and E. coli, B. cereus, and S. cerevisiae were seeded on MPA. The plates with medium inoculated microorganisms were placed in a discharge chamber under plasma jets. Plasma-treated media were incubated in an incubator within $24 \mathrm{~h}$ at $37^{\circ} \mathrm{C}$, and then, the diameters of inactivation zone were measured.

\section{Treatment conditions}

Plasma jet operated at current of $0.5 \mathrm{~mA}$, voltage of $1.7 \mathrm{kV}$, and argon flow rate of $6.7 \mathrm{l} / \mathrm{min}$ for all treatments. An increase in the gas temperature at such discharge parameters does not exceed $0.01{ }^{\circ} \mathrm{C}$. The plasma jet length was $\sim 1.0 \mathrm{~cm}$. Each experiment was performed in triplicate to ensure reproducibility, and the plasma plume was directed perpendicular to the surface of the agar plates. Microorganisms were exposed to the plasma jet for $5,10,30,60,120,240$, and $360 \mathrm{~s}$. The treatments were carried out at three different distances between the nozzle and the agar $(0.5,2.0$ and $3.0 \mathrm{~cm})$. For the control experiments, the samples were exposed to argon flow at the same flow rate without plasma ignition.

\section{Results and discussion}

The bactericidal properties of low-current spark discharge plasma jets were studied for their effects on the $E$. coli strains. Figure 2 shows a picture of low-current spark discharge cold argon plasma jet generator. Low-current spark discharge plasma jetting time ranged from 5 to $60 \mathrm{~s}$. Distance $h$ from the plasma source to the surface of microorganism growth ranged from 0.5 to $3 \mathrm{~cm}$.

The current-voltage characteristic of discharge is dropping, and the nature of current flow in the plasma channel is an established mode of periodical current pulses (Fig. 3). In the formation of discharge current pulse, two specific areas can be marked out: the initial narrow peak with amplitude $\operatorname{Im} \sim 280 \mu \mathrm{A}$ (area 1) and the second longer area (T $70 \mu \mathrm{s})$ that essentially determines the period $\mathrm{T}$ of discharge current pulse. The low-current spark plasma jetting influence on microorganisms is registered as round transparent areas, which are the microorganism's growth inactivation zones.

The data obtained show high sensitivity of microorganisms to cold argon plasma treatment (Fig. 4). Minimal plasma inactivation time of the $E$. coli cells is $5 \mathrm{~s}$ at $0.5 \mathrm{~cm}$ from the side section of electrode structure. At a distance increased to $3 \mathrm{~cm}$, the number of survived microorganism

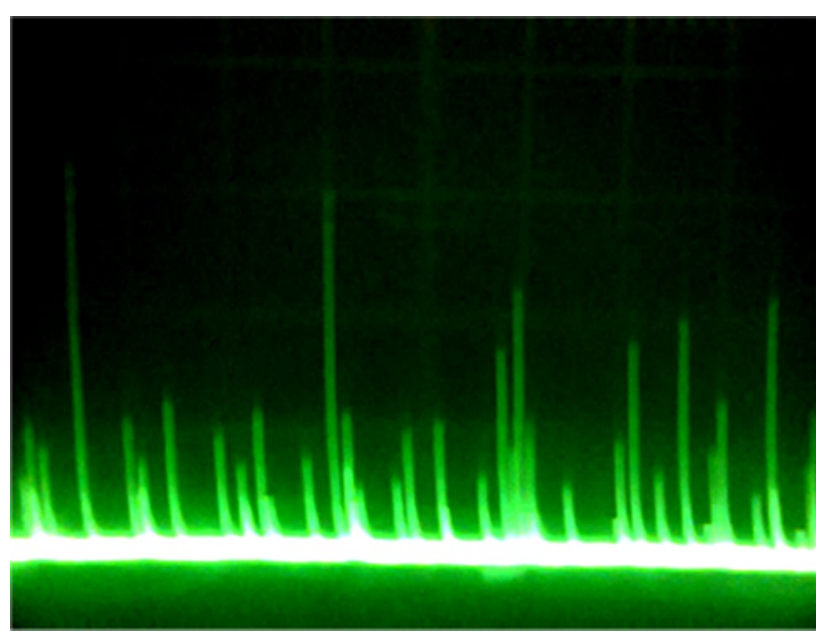

Fig. 3 Low-voltage spark discharge current pulses. Interelectrode spacing $d=1.25 \mathrm{~cm}$, amperage $I=500 \mu \mathrm{A}, \mathrm{R} \sigma=21 \mathrm{M} \Omega,[I]=50 \mu \mathrm{A} /$ div, $[t]=0.2 \mathrm{~ms} / \mathrm{div}$
Fig. 2 Cold argon plasma generator based on low-current spark plasma jets: a microorganism inactivation in a Petri dish and $\mathbf{b}$ side view of discharge
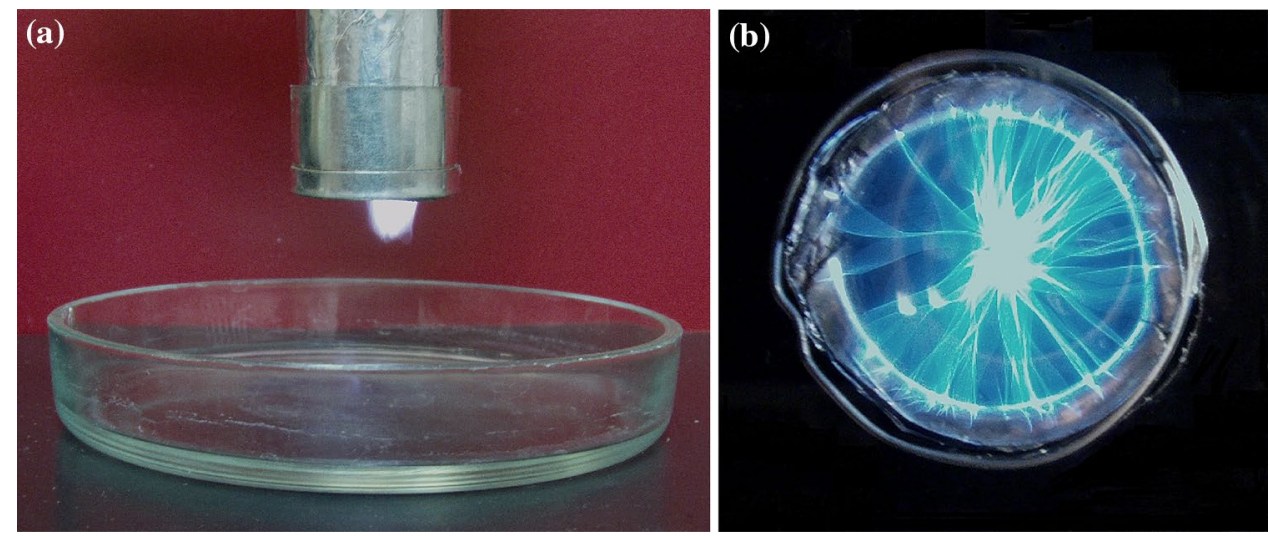


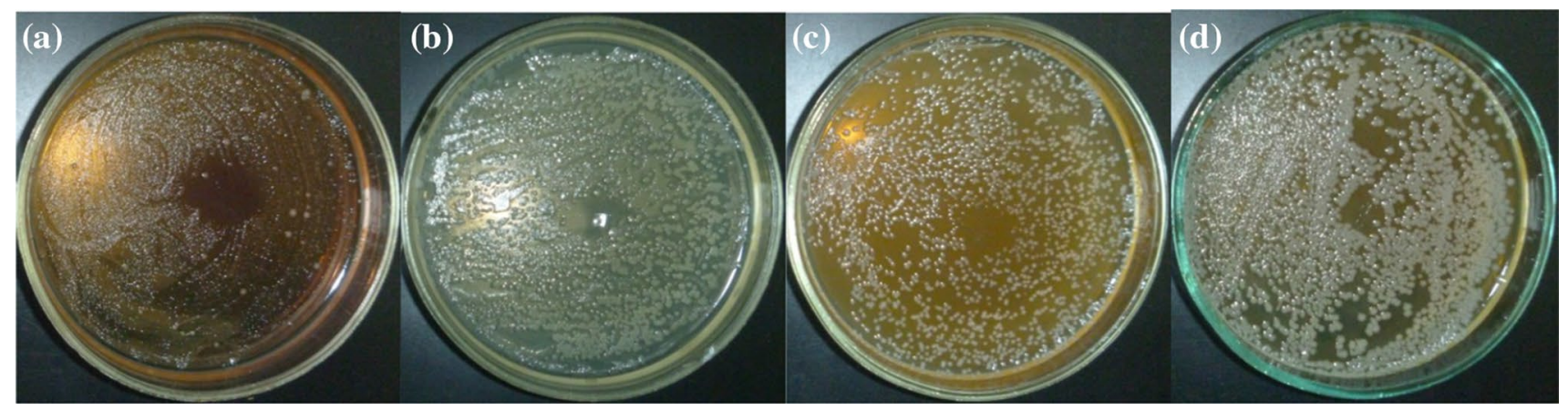

Fig. 4 Bacterial growth inactivation area's treatment time $t=4 \mathrm{~min}$, distance $h=0.5 \mathrm{~cm}$ : a Escherichia coli; $\mathbf{b}$ Bacillus subtilis; $\mathbf{c}$ Saccharomyces cerevisiae; $\mathbf{d}$ Bacillus cereus

is considerably greater. Increasing the plasma treatment time up to $40 \mathrm{~s}$ at a distance of $3 \mathrm{~cm}$ causes a considerable reduction (by 74\%) in survived microorganisms (Fig. 5). The determination of argon plasma inactivation ability carried out by counting the colonies shows that after a minute of treatment, only a few grown-up microorganisms survive.

It should be noted that the inactivation area is not restricted by the anode diameter, within which low-current spark plasma jets are formed. As it can be seen in Fig. 6, increasing the treatment time with low-current spark plasma jets allows efficient inactivation of a much larger area. At that, the diameter of inactivation area in direct contact of plasma jets with the surface of microbial environment increases more than in remote exposure. The results obtained correspond to the results shown in [18]. So, the diameter of inactivation area increases with increasing time of treatment of Pseudomonas aeruginosa bacteria on solid agar with atmospheric-pressure cold plasma jets ( $99.5 \%$ helium and $0.5 \%$ oxygen).

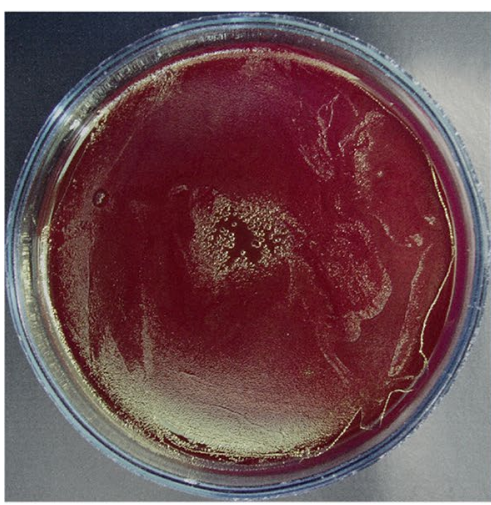

(1a)

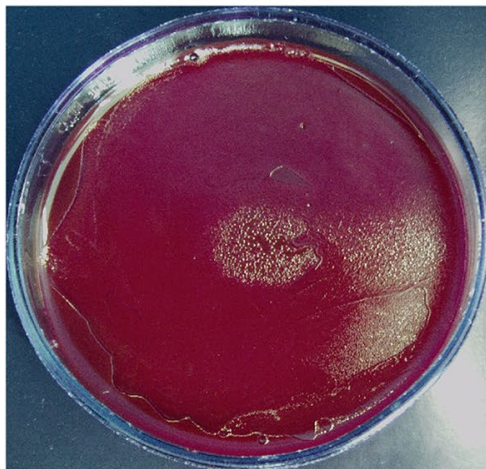

(2a)

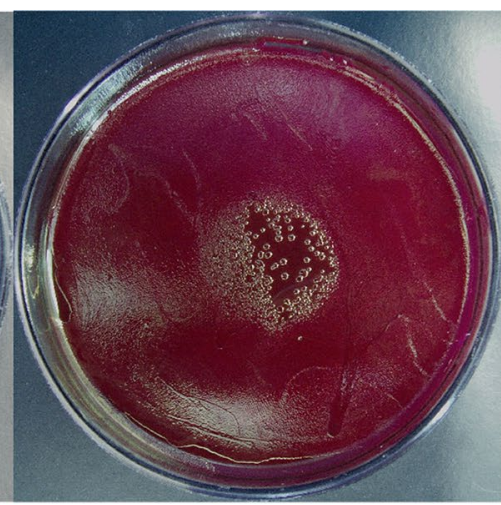

(1b)

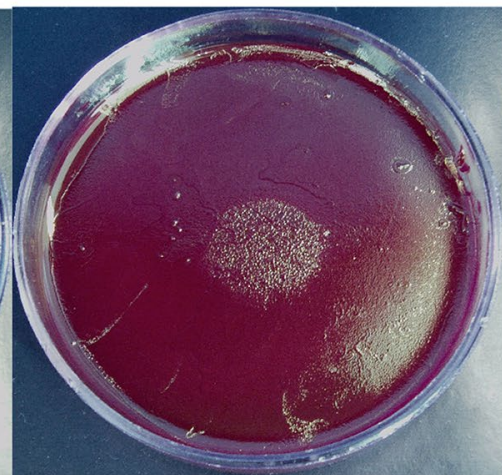

(2b)

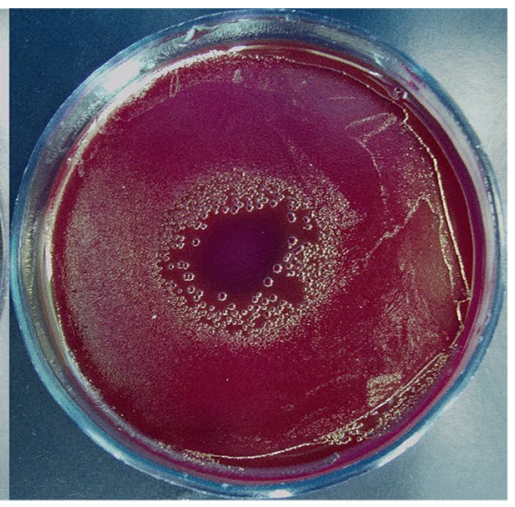

(1c)

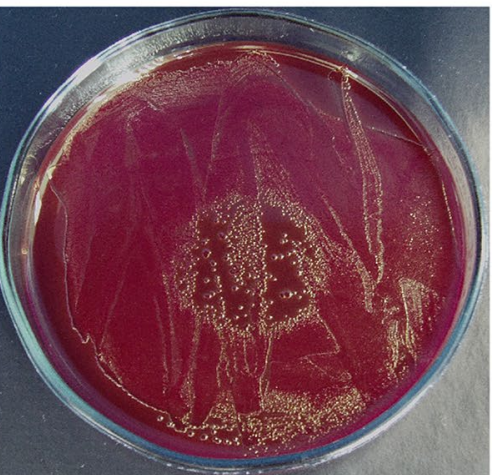

(2c)

Fig. 5 E. coli growth inactivation areas in relation to $h$ : (1) $h=1.0 \mathrm{~cm},(2) h=2.0 \mathrm{~cm}, \mathbf{a} t=5 \mathrm{~s} ; \mathbf{b} t=20 \mathrm{~s}, \mathbf{c} t=60 \mathrm{~s}$ 


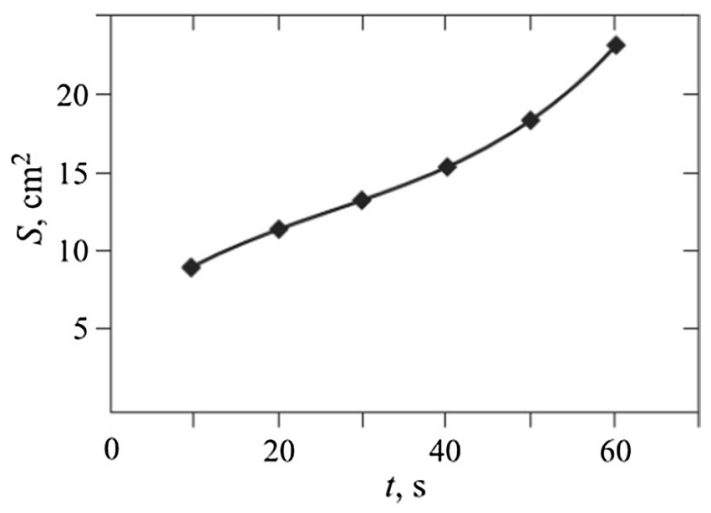

Fig. 6 The relationship of inactivation area of Escherichia coli and exposure time, $h=0.5 \mathrm{~cm}$

\section{Conclusions}

The high bactericidal efficiency of low-current high-voltage discharge cold argon plasma is displayed. The study of bacterial survival in the repetitively pulsed negative corona plasma and atmospheric-pressure glow discharge showed that after treating the wafers for $2 \mathrm{~min}$ in each mode, the microorganisms are totally inactivated. It has been found that increasing the time of microbial environment treatment with low-current spark plasma jets allows efficient inactivation of a much larger area than the anode electrode cross section.

Acknowledgements This work is supported by the Basic Research Program of the SB RAS II.9 (Project 0336-2019-0009).

Open Access This article is distributed under the terms of the Creative Commons Attribution 4.0 International License (http://creativeco mmons.org/licenses/by/4.0/), which permits unrestricted use, distribution, and reproduction in any medium, provided you give appropriate credit to the original author(s) and the source, provide a link to the Creative Commons license, and indicate if changes were made.

\section{References}

1. Heinlin, J., Isbary, G., Stolz, W., et al.: Plasma applications in medicine with a special focus on dermatology. J. Eur. Acad. Dermatol. Venereol. 25, 1 (2011)

2. Sohbatzadeh, F., Hossienzadeh Colagar, A., Mirzanejhad, S., et al.: E. coli, $P$. aeruginosa, and B. cereus bacteria sterilization using afterglow of non-thermal plasma at atmospheric pressure. Appl. Biochem. Biotechnol. 160, 1978 (2010)
3. Fridman, G., Vasilets, V., Gutsol, A., et al.: Blood coagulation and living tissue sterilization by floating-electrode dielectric barrier discharge in air. Plasma Process. Polym. 5, 503 (2008)

4. Kalghatgi, S.U., Fridman, G., Cooper, M., et al.: Mechanism of blood coagulation by nonthermal atmospheric pressure dielectric barrier discharge plasma. IEEE Trans. Plasma Sci. 35, 1559 (2007)

5. Weltmann, K.D., Kindell, E., Woedtke, T., et al.: Atmosphericpressure plasma sources: prospective tools for plasma medicine. Pure Appl. Chem. 82, 1223 (2010)

6. Lu, X., Laroussi, M., Puech, V.: On atmospheric-pressure nonequilibrium plasma jets and plasma bullets. Plasma Sour. Sci. Technol. 21, 034005 (2012)

7. Arkhipenko, V.I., Kirillov, A.A., Safronau, Y.A., et al.: DC atmospheric pressure glow microdischarges in the current range from microamps up to amperes. Eur. Phys. J. D 60, 455 (2010)

8. Morent, R., de Geyter, N.: Chap. 2: inactivation of bacteria by non-thermal plasmas. In: Fazel-Rezai, R. (ed.) Biomedical engineering - frontiers and challenges. InTech, Chennai (2011)

9. Machala, Z., Hensel, K., Akishev, Yu.: Plasma for bio-decontamination, medicine, and food security. NATO Sci. Peace Secur. Ser. A Chem. Biol. 17, 479 (2012)

10. Baldanov, B.B.: Experimental study of a multipoint cathode corona in an argon flow. Plasma Phys. Rep. 35, 603 (2009). (in Russian)

11. Kirillov, A.A., Pavlova, A.V., Safronov, E.A., et al.: DC atmospheric pressure glow discharge plasma jet application for Staphylococcus aureus inactivation. Appl. Phys. 5, 52 (2013). (in Russian)

12. Akan, T., Çabuk, A.: Indirect plasma inactivation by a low temperature atmospheric pressure plasma (LTAPP) system. J. Electrostat. 72, 218 (2014)

13. Solís-Pacheco, J.R., Aguilar-Uscanga, B.R., Villanueva-Tiburcio, J.E., et al.: Effect and mechanism of action of non-thermal plasma in the survival of Escherichia coli, Staphylococcus aureus and Saccharomyces cerevisiae. J. Microbiol. Biotechnol. Food Sci. 7, 137 (2017)

14. Baldanov, B.B., Semenov, A.P., Ranzhurov, T.V., et al.: Action of plasma jets of a low-current spark discharge on microorganisms (Escherichia coli). Tech. Phys. 60, 1729 (2015). (in Russian)

15. Silhavy, T.J., Kahne, D., Walker, S.: Cold spring harbor perspect. Perspect. Biol. 2, 1 (2010)

16. Nishime, T.M.C., Borges, A.C., Koga-Ito, C.Y., et al.: Non-thermal atmospheric pressure plasma jet applied to inactivation of different microorganisms. Surf. Coat. Technol. 312, 19 (2017)

17. Ruiz-Herrera, J.: Fungal cell wall: structure, synthesis, and assembly, 2nd edn. CRC Press, Boca Raton (2012)

18. Cabiscol, E., Tamarit, J., Ros, J.: Oxidative stress in bacteria and protein damage by reactive oxygen species. Int. Microbiol. 3, 3 (2000)

Publisher's Note Springer Nature remains neutral with regard to jurisdictional claims in published maps and institutional affiliations. 